\title{
Oxytocin and obesity: 2015-2017 literature review on oxytocin use in obese women
}

\author{
Annessa Kernberg* \\ Oregon Health and Science University, USA
}

\begin{abstract}
As obesity becomes more prevalent, research regarding oxytocin use is increasing as well. A literature review from 2015-2017 assessing oxytocin use in obesity highlighted this evolving field. Body Max Index (BMI) alone appears to contribute to blunted myometrial and therefore contractile responses seen in obese women. The interplay of elevated progesterone and leptin contribute to this phenomenon, and maybe explain the elevated oxytocin dosing seen amongst this population. None the less, the effects of obesity on the mode of delivery is still controversial, with some investigators claiming the interval from induction to delivery, delivery within 24 hours, vaginal delivery within 24 hours, and the cesarean delivery rate did not vary between stratified classes of obesity. Conversely, the authors concluded that as BMI increases the women undergoing induction with misoprostol have a longer time to delivery, require greater quantities of misoprostol, longer duration of oxytocin, and increased cesarean section rates. Amongst the literature, there is a consistent message that obese women are somehow different. Investigating the information retrospectively highlights areas, which necessitate prospective trails and assessment.
\end{abstract}

\begin{abstract}
Abbreviations and symbols: BMI: Body Mass Index, CI: Confidence Interval, PROM: Premature Rupture of Membranes
\end{abstract}

\section{Introduction}

As obesity becomes more prevalent, research regarding oxytocin use in this population is increasing. In the most recent National Center for Health Statistics (NCHS) the prevalence of obesity amongst women aged 20-39 was $36.5 \%$ and from 1999-2000 through 2015-2016, a significantly increasing trend in obesity was observed in both adults and youth [1]. Complications of maternal obesity include maternal complications such as gestational diabetes mellitus, hypertensive disorders in pregnancy, and long-term cardiovascular implications, as well fetal complications including stillbirth, macrosomia, childhood obesity, and others [2-5]. Due to these complications, obese women are at risk of labor induction and subsequent failure [6]. It appears obesity impacts progression of labor with longer median duration when compared to normal weight women [7]. This phenomenon is multifactorial though oxytocin pharmacokinetics and metabolism differ. Reviewing the literature regarding this specific patient population allows reflection on current advances and directs future research in hopes of optimizing oxytocin administration and clinical care.

\section{Materials and methods}

A literature review of studies between the years 2015 to 2017 was conducted. Keywords words such as oxytocin, obesity, induction of labor, and augmentation of labor were used in PubMed. The analysis involved eight articles, with a selected subset of six pertaining to oxytocin and obesity. Of these six articles, there was five retrospective cohort studies and a single randomized control trial. The following paper reviews the most recent literature regarding oxytocin use in obese women.

\section{Results}

Oxytocin response is unpredictable and further studies are needed to investigate the characteristics that determine the sensitivity or blunting of response, which is thought to occur in obesity. Carlson NS et al. specifically examined 136 spontaneous laboring obese women $\left(\mathrm{BMI} \geq 30 \mathrm{~kg} / \mathrm{m}^{2}\right)$ undergoing augmentation with regards to hourly doses of oxytocin. After controlling for maternal, fetal, and labor characteristics, BMI alone explained 16.56\% (95\% Confidence Interval (CI)13.7-20.04) of the variance in hourly oxytocin doses. The authors concluded, obesity contributes to blunting of myometrial contractility and therefore a response to oxytocin [8]. This effect was seen in Hill M et al. study as well. In a retrospective review, amongst a cohort of 54term women undergoing induction of labor with subsequent vaginal deliveries, obese women $\left(\mathrm{BMI}>40 \mathrm{~kg} / \mathrm{m}^{2}\right)$ required more oxytocin than lean women during the first stage of labor when matched for parity, diabetes, epidural use, birth weight, pre-induction dilatation, and station [9]. In attempts of explaining this phenomenon, HajagosToth et al. reviewed the influences of increased body weight on multiple endocrine and paracrine systems. For example, increased body weight leads to elevations in progesterone, which contribute to poor contractility. Obesity also increases leptin, which inhibits both spontaneous and augmented or induced uterine contractions in animal models as well as isolated human myometrium [10]. These articles highlight the complexity of obesity on oxytocin administration, efficacy, and management.

Whether obesity impacts mode of delivery for women undergoing induction of labor is still controversial. In a randomized control trial conducted by Mackeen et al., 201 women underwent randomization between induction with concurrent Foley catheter and oxytocin versus oxytocin alone. The women were stratified based on BMI into the

Correspondence to: Annessa Kernberg, Oregon Health and Science University, Portland, USA, E-mail: kernberg@ohsu.edu

Key words: oxytocin, obesity, augmentation of labor, induction of labor

Received: November 28, 2017; Accepted: December 20, 2017; Published: December 23, 2017 
following groups: BMI $<25 \mathrm{~kg} / \mathrm{m}^{2}$, overweight (BMI 25 to $<30 \mathrm{~kg} /$ $\mathrm{m}^{2}$ ), class I obese (BMI 30 to $<35 \mathrm{~kg} / \mathrm{m}^{2}$ ), class II (BMI 35 to $<40 \mathrm{~kg} /$ $\left.\mathrm{m}^{2}\right)$, class III (BMI $\left.\geq 40 \mathrm{~kg} / \mathrm{m}^{2}\right)$. Results, regardless of BMI, were not significant for the interval from induction to delivery, delivery within 24 hours, vaginal delivery within 24 hours, and cesarean delivery rate. Specifically, these women presented with premature rupture of membranes (PROM) [11]. In a retrospective review, Maeder et al. investigated 280 women undergoing induction secondary to postdates who were overweight (BMI 25 to $29.99 \mathrm{~kg} / \mathrm{m}^{2}$ ) or obese (BMI $\geq 30$ $\mathrm{kg} / \mathrm{m}^{2}$ ). Results were consistent with previous studies demonstrating the increased oxytocin quantities, but conflicted with Maeder et al., demonstrating longer durations of labor and greater cesarean rates. Interestingly, the studied reviewed units of oxytocin per hour of infusion and while obese women received an increased quantity of oxytocin in labor, they may not have received adequate units of oxytocin per hours of infusion [12]. On the other hand Lassiter JR et al., retrospectively reviewed a cohort over two years who were $>37$ weeks of gestational age and had a Bishop score less than five prior starting an induction of labor. The 329 patients were stratified based on their BMI categories of BMI $\leq 30 \mathrm{~kg} / \mathrm{m}^{2}$, BMI 30 to $39.9 \mathrm{~kg} / \mathrm{m}^{2}$, and $\mathrm{BMI} \geq 40 \mathrm{~kg} / \mathrm{m}^{2}$. The groups were consistent with regards to gestational age, Bishop score, median parity, and race. Conversely, the authors concluded that as BMI increases the women undergoing induction with misoprostol have a longer time to delivery, require greater quantities of misoprostol, longer duration of oxytocin, and increased cesarean section rates [13]. These results beg to question if a specific oxytocin protocol for obese women is in order, which includes stratifying BMI and oxytocin administration with greater consistency.

\section{Discussion}

These articles have limitations. First, the majority of the research is retrospective with only a single prospective trial. Amongst the trials, BMI stratification was not consistent. Carlson et al. and Hill et al. use a single variable cutoff though they differ in value between $\mathrm{BMI} \geq 30$ $\mathrm{kg} / \mathrm{m}^{2}$ and $\mathrm{BMI}>40 \mathrm{~kg} / \mathrm{m}^{2}$. With a single value cutoff, results may be inaccurate as higher BMI individuals are grouped with lower BMI individuals, which can skew the results. The other studies further stratify BMI though to a variable degree with Mackeen et al. having four classes, and others only having three. This variation may inhibit comparison amongst the studies. Second, the BMI $>40 \mathrm{~kg} / \mathrm{m}^{2}$ group includes a wide range of BMI individuals which none of the studies subdivided and therefore results within this category are inconclusive. Thirdly, the single prospective study specifically assessed obese women presenting with PROM, and therefore the information is not generalizable to obese women undergoing induction of labor for other indications. Lastly, the number of individuals within the studies is relatively small, and this also hinders generalizability.

The articles' strongest attribute is the consistent message that obese women are somehow different. Investigating the information retrospectively highlights areas, which necessitate prospective trails and assessment. Ideally collecting a large patient population across geographical locations with consistent BMI groups enables greater generalizability. Starting with basic science research, the pathogenesis of obesity derived myometrial blunting to clinical outcomes, oxytocin use in obese women is an evolving area of research.

\section{References}

1. Hales CM, Carroll MD, Fryar CD, Ogden CL (2015) Prevalence of obesity among adults and youth: The United States. NCHS Data Brief 219: 1-8. [Crossref]

2. Wankhade UD, Thakali KM, Shankar K (2016) Persistent influence of maternal obesity on offspring health: Mechanisms from animal models and clinical studies. Mol Cell Endocrinol 435: 7-19. [Crossref]

3. Moussa HN, Alrais MA, Leon MG, Abbas EL, Sibai BM (2016) Obesity epidemic: impact from preconception to postpartum. Future Sci OA 2: [Crossref]

4. Overcash RT, Lacoursiere DY (2014) The clinical approach to obesity in pregnancy. Clin Obstet Gynecol 57: 485-500. [Crossref]

5. Carlson NS, Hernandez TL, Hurt KJ (2015) Parturition dysfunction in obesity: time to target the pathobiology. Reprod Biol Endocrinol 13: 135. [Crossref]

6. Nuthalapaty FS, Rouse DJ, Owen J (2004)The Association of Maternal Weight with Cesarean Risk, Labor Duration, and Cervical Dilation Rate. Obstet Gynecol 103: 452456. [Crossref]

7. Vahratian A, Zhang J, Troendle JF, Savitz DA, Siega-Riz AM (2004) Materna Prepregnancy Overweight and Obesity and the Pattern of Labor Progression in Term Nulliparous Women Obstet Gynecol 104: 943-951. [Crossref]

8. Carlson, Corwin EJ, Lowe NK (2017) Oxytocin Augmentation in Spontaneously Laboring, Nulliparous Women: Multilevel Assessment of Maternal BMI and Oxytocin Dose. Biol Res Nurs 19: 382-392 [Crossref]

9. Hill M, Reed KL, Cohen WR (2015) Oxytocin utilization for labor induction in obese and lean women. J Perinat Med 43: 703-706. [Crossref]

10. Hajagos-Tóth J, Ducza E, Samavati R, Vari S, Gaspar, (2017) Obesity in pregnancy: a novel concept on the roles of adipokines in uterine contractility. Croat Med J 58: 96-104. [Crossref]

11. Mackeen A, Dhanya MD, Danielle, Lin, Monique et al. (2017) Effect of Obesity on Labor Inductions with Foley Plus Oxytocin Versus Oxytocin Alone. Obstetrics \& Gynecology

12. Maeder AB, Vonderheid SC, Park CG, Bell AF, McFarlin BL, et al. (2017) Titration of Intravenous Oxytocin Infusion for Postdates Induction of Labor Across Body Mass Index. Groups J Obstet Gynecol Neonatal Nurs 46: 494-507. [Crossref]

13. Lassiter JR, Holliday N, Lewis DF, Mulekar M, Abshire J, et al. (2016) Induction of labor with an unfavorable cervix: how does BMI affect success?. The Journal of Maternal-Fetal \& Neonatal Medicine: J Matern Fetal Neonatal Med 29: 3000-3002 [Crossref]

Copyright: (C2017 Kernberg A. This is an open-access article distributed under the terms of the Creative Commons Attribution License, which permits unrestricted use, distribution, and reproduction in any medium, provided the original author and source are credited. 